\title{
EDUCAÇÃO PROFISSIONAL: ANÁLISE DAS COMPETÊNCIAS PROFISSIONAIS DO ANIMADOR TURÍSTICO NA HOTELARIA DA GRANDE FORTALEZA
}

\author{
Ermini Guimarães Cordeiro ${ }^{1}$ \\ Marcel Pereira Pordeus ${ }^{2}$
}

RESUMO: Este artigo é uma síntese da minha tese de doutorado em Ciências da Educação, pela Universidad Interamericana. Para tanto, permeamos a formação em educação profissional e a análise da definição das competências profissionais necessárias para o exercício profissional do animador turístico na rede hoteleira de Fortaleza, e como constituem o objeto de estudo da presente tese de doutorado em ciências da educação. Estão contemplados no trabalho os aspectos da formação do trabalhador em contexto de mudança tecnológica e a evolução da animação turística, aliados a prática do referido profissional. A presente pesquisa desenvolve e define o perfil do animador turístico, função, os tipos de animação e a formação necessária para desempenhar a profissão com eficiência, consubstanciando as novas dinâmicas do lazer. Esta pesquisa acadêmica foi realizada a partir experiências vivenciadas na rede hoteleira em nível nacional e internacional. A metodologia aplicada foi de cunho qualitativo, definida como estudo de caso, avaliando a animação turística a partir da análise de cinco grandes hotéis ou resorts de Fortaleza. A pesquisa organizou-se em três eixos: pesquisa bibliográfica, documental e de campo. Chegamos a conclusão de que a animação turística, apesar de ser um produto em ascensão no Brasil e especialmente no Ceará, esta apresenta deficiência no tocante a formação do profissional qualificado, capaz de atender a demanda, tornando-se então urgente promover um processo formativo que a contemple continuamente.

Palavras-chave: Formação continuada. Educação. Animação turística.

\section{INTRODUÇÂO}

Nos últimos anos, o turismo tem se posicionado como um dos setores mais importantes da economia no Ceará. Os dados apresentados pela SETUR (2008) revelam elevadas taxas de crescimento, tanto em número de turistas como no gasto que estes efetuam. Em consequência disto, o setor hoteleiro passa por importantes mudanças. $O$ avanço notificado no turismo como setor da economia no Ceará tem levado alguns

\footnotetext{
${ }^{1}$ Mestrado Profissional em Gestão de Negócios Turístico pela Universidade Estadual do Ceará (2005). Atualmente é Técnico Em Assuntos Educacionais-Pedagoga do Instituto Federal do Ceará - Reitoria. Tem experiência na área de Educação, com ênfase em Orientação e Aconselhamento. E-mail: danielgc849@gmail.com.

${ }^{2}$ Mestre em Planejamento e Políticas Públicas pela Universidade Estadual do Ceará (UECE) - Graduado em Letras: Português / Literaturas pela Universidade Federal do Ceará (UFC). Graduando em Gestão Pública pela Pontifícia Universidade Católica do Paraná(PUCPR).E-mail: marcel.pordeus@aluno.uece.br.
} 
empresários a iniciarem uma nova proposta de férias, baseada no conceito de lazer ativo (firmado em atividades onde o indivíduo realiza movimentos corporais integrais ou parciais). Puseram a ênfase na animação turística que se introduz em sua própria estrutura como um conceito de qualidade e de distinção em relação aos demais estabelecimentos hoteleiros.

É desta maneira que se oferece ao cliente a oportunidade de optar entre uma atitude passiva e outra dinâmica que lhe permita renovar não só as energias físicas gastas durante o ano, mas algo mais importante, que lhe permita trabalhar a sua própria atitude anímica. Atualmente, a profissão de animador turístico está se consolidando, e a rede hoteleira não somente necessita de um animador, mas, frequentemente, de uma equipe de animação. Conforme esclarecimentos da SETUR (2008), os animadores turísticos aparecem com um novo perfil profissional na hotelaria, necessitando de uma maior especialidade e profissionalização.

O desenvolvimento adequado da equipe de animação na rede hoteleira deve permitir uma oferta de lazer mais relacionada com a realidade local, mais ligada à oferta cultural, ao meio ambiente local, entre outros. Enfim, mais capacitação para dar respostas às necessidades diferenciais apresentadas por diversos tipos de clientes, como crianças, jovens, idosos e adultos, como resposta aos desejos de atividade e lazer.

O objetivo da animação é humanizar mais as viagens, oferecendo ao turista a possibilidade de participação ativa, de tornar-se protagonista das férias, nos meios de hospedagens e nos transportes de longo curso, através de programas de cunho cultural, social, recreativo e esportivo. A animação turística pode ter um papel determinante na redução de agressões que sofrem o patrimônio histórico e ambiental, principalmente na cidade de Fortaleza-CE, ambiente deste estudo. A elaboração e execução de programas de animação no turismo e hotelaria exigem um conhecimento específico de técnicas, de planejamento, e um conhecimento do ambiente turístico. Faz-se necessária uma preparação adequada para que o profissional possa desempenhar a sua função a contento.

As atividades de animações turísticas, em Fortaleza, têm sido desenvolvidas por pessoas que respondem a um perfil concreto, que faz com que tenham importantes habilidades para o desenvolvimento do trabalho. Porém, frequentemente não têm uma formação adequada, visto que não existe uma formação com normas específicas e necessárias, podendo pertencer a muitos campos formativos diferentes, tornando-se difícil 
obter o resultado satisfatório. A emergência de identificação do perfil, e ao mesmo tempo, as necessidades de capacitação dos técnicos em animação turística, faz com que a definição de competências ${ }^{3}$ requeridas para o exercício da atividade e os percursos formativos para conseguir a qualificação exigida, seja especialmente importante.

Conforme as Diretrizes Curriculares Nacionais para Educação apresentada nos Parâmetros Curriculares Nacionais de 2013, a qualificação para o trabalho constitui não apenas como sinônimo de preparação para execução de um determinado conjunto de tarefas, mas a qualificação para o trabalho exige para além do domínio operacional de um determinado fazer, a apropriação de um saber tecnológico e a reelaboração de uma cultura do trabalho. Tomando por bases as considerações citadas, pode-se dizer que a atividade turística está passando por constantes transformações quanto aos contextos geográficos, culturais, sociais e atividades de entretenimento.

Os turistas podem encontrar outras motivações, além do sol e praia para o lazer. Hoje em dia, encontra-se num processo de valorização, o ato turístico (do lazer ativo e participativo, interagindo com a comunidade local) na procura de novas formas de lazer como as manifestações lúdicas, práticas desportivas, (desporto radical e turismo de aventura e a descoberta da natureza e do patrimônio) turismo ambiental e cultural.

Os métodos de investigação foram trabalhados assumindo-se as seguintes hipóteses em relação à rede hoteleira de Fortaleza: as atividades desenvolvidas pelo Animador Turístico não satisfaz plenamente ao cliente; as instruções profissionalizantes ainda não atentaram para o mercado do profissional de Animador Turístico; as estruturas físicas dos hotéis possuem espaços ociosos ou mal utilizados que poderiam ser adaptados para atender o requisito de animação; não existe em Fortaleza nenhum curso regular que capacite o Animador Turístico; a Coordenação da Animação Turística dos hotéis não são da área específica de Animação e não possui vivência no setor; os hoteleiros visam o lucro e não a qualidade de seus serviços, preferindo admitir universitário e utilizando os serviços dos estagiários para realizar a função de Animador; a capacitação do Animador Turístico é inadequada para o desempenho da função.

O presente estudo concentrou-se na definição das competências profissionais

\footnotetext{
${ }^{3}$ Competência é o substantivo feminino com origem no termo em latim competere que significa uma aptidão para cumprir alguma tarefa ou função. Também é uma palavra usada como sinônimo de cultura, conhecimento e jurisdição.
} 
necessárias para o exercício da profissão do Animador Turístico nos hotéis de Fortaleza, já que a indefinição existente do perfil profissional do animador turístico dificulta o estabelecimento das necessidades formativas dos mesmos. Uma vez analisado o perfil profissional do Animador Turístico, competências e o desenvolvimento de conhecimentos, habilidades e atitudes exigidas, propõe-se definir o processo de formação para se obter a qualificação na profissão do Animador Turístico.

Os estudos efetuados por especialistas em turismo dão conta de que os animadores turísticos não se encontram capacitados para atuarem no mercado de trabalho, e que os empresários ainda não atentaram para o fato de que os Animadores Turísticos estão necessitando urgentemente de uma formação continuada, a fim de atenderem a contento a rede hoteleira de Fortaleza. Por outro lado, no trabalho como pedagoga do Instituto Federal do Ceará (IFCE), Instituição considerada como referência em educação profissional, percebe-se que o mesmo não dispõe de um curso técnico ou tecnológico na área de Animação Turística para que possa atender a esta clientela.

Frente a problemática anteriormente citada, pergunta-se: Que atividades o Animador Turístico deveria desenvolver que viesse satisfazer o cliente (turista)? $O$ que as instituições profissionalizantes precisam fazer para oferecer uma maior estrutura de formação ao Animador Turístico? Há necessidade da implantação de um curso técnico ou tecnológico na área de Animação Turística no IFCE? Como os hotéis poderão superar o problema da falta de um espaço propício ao desenvolvimento de atividades no campo da animação turística? O que se deve fazer para que a Coordenação da Animação Turística possa se especializar e ter vivência na especificada área? $O$ que fazer para que os empresários integrem lucro e qualidade nos empreendimentos no setor de Animação Turística?

Neste contexto é que se fundamenta a necessidade de um estudo aprofundado sobre a prática do profissional que atua na rede hoteleira de Fortaleza, e a necessidade de promover em nível da estrutura turística e hoteleira, a capacitação de um corpo profissional que possa desempenhar o seu papel de animador turístico com eficiência, consubstanciando as novas dinâmicas de lazer. Este serviço oferecido pela rede hoteleira tem sido mais um produto diferencial a ser oferecido pelos empresários hoteleiros. A animação turística, além de ser um elemento de marketing e promoção, pode causar muito mais impacto do que qualquer outra propaganda. 
Desta forma, a animação turística tem o potencial de captar novos clientes, aumentando a procura pelo hotel. Em função da complexidade que o tema abordado em pesquisa possui, e em virtude da perspectiva de se lançar uma proposta de trabalho colocando em evidência a importância que possui o Animador Turístico, propõe-se o desenvolvimento do presente estudo, fazendo uso neste aspecto de uma apreciação bibliográfica firmada em concepções de estudiosos como Barreto (2006), Trigo (2009), entre outros listados constituidores do marco teórico da pesquisa. Com a seguinte pergunta de partida: Quais as competências profissionais do animador turístico que podem ser percebidas a partir da hotelaria da grande Fortaleza?

\section{A FORMAÇÃO DO TRABALHADOR EM CONTEXTO DE MUDANÇA TECNOLÓGICA: CONCEITO E REVISÃO DA LITERATURA}

Nesta seção propõe-se fazer uma abordagem sobre a formação do trabalhador em contexto de mudança tecnológica. Focalizando neste sentido o problema das relações entre educação e trabalho, as novas tecnologias na educação e finalmente o ensino do turismo no contexto da pós-modernidade. Nos últimos tempos tem se colocado em discussão, nos

debates e encontros sobre a formação dos profissionais, o problema das relações entre educação e trabalho com diferentes abordagens; uma das concepções da atualidade é que a educação tende a coincidir com escola, sendo dominante a tendência de situar a educação no âmbito do não trabalho, tendo assim um caráter improdutivo.

Segundo Saviani (2009), com o surgimento da "Teoria do Capital humano", (década de 6o), a educação passou a ser vista como algo decisivo para o desenvolvimento econômico. Postula-se assim, uma grande ligação entre educação (escola) e trabalho; isto é, considera-se que a educação potencializa o trabalho. Os críticos da "Teoria do Capital humano" consideram que a educação é funcional ao sistema capitalista, enquanto qualificadora de mão-de-obra (força de trabalho) contribuindo para o desenvolvimento econômico.

Os educadores, de um modo geral, têm oscilado entre as duas concepções opostas. Uma considera que a educação deve ser em termos gerais com ou sem referências à formação profissional. Em oposição, a outra concepção propõe um sistema dualista com a formação geral desvinculada da formação profissional. Ou mesmo concebendo uma escola única que possa articular educação geral e formação profissional.

Saviani (2009) ressalta que, na Idade Média, as escolas se destinavam à educação da 
classe dominante. As atividades se constituíam em formas de ocupação do ócio como na antigüidade. Então, ocupar o ócio com os estudos significava não precisar trabalhar para suprir as necessidades da existência. Ocupar o tempo com atividades nobres e não com atividades consideradas indignas (arte militar e o da vida aristocrática). Em contrapartida, a grande maioria continuava se educando pelo trabalho, o processo de produzir a própria existência e de seus senhores. Nesse contexto, a forma escolar da educação é ainda uma forma secundária que se contrapõe como não-trabalho à forma de educação dominante determinada pelo trabalho.

O autor supracitado salienta ainda que, a referência de vida da Idade Média era o campo que se contrapunha à cidade onde se desenvolvia apenas o artesanato. Este é uma espécie de indústria rural, de indústria própria da agricultura. $\mathrm{O}$ desenvolvimento das atividades artesanais, fortalecendo as corporações de ofícios, aliado ao grau de acumulação que a economia feudal pôde desenvolver, possibilitou o crescimento de uma atividade mercantil que está na origem da constituição do capital. Através do comércio o homem burguês foi acumulando capital, que em seguida passou a ser investido na própria produção, originando assim a indústria. Tem-se então, a partir desse processo, a constituição de um modo de produção que é capitalista ou burguês, ou modo de produção moderno.

Neste contexto, tomando por base as considerações destacadas por Saviani (2009), pode-se dizer que o advento da indústria conduziu a uma crescente simplificação do trabalho e a redação da qualificação específica. Isto foi possível com a introdução da maquinaria que passou a executar a maior parte das funções manuais. Tal processo ganhou ênfase com a chamada "Revolução Industrial", que data do final do século XVIII e a primeira metade do século XIX.

$\mathrm{Na}$ opinião de Saviani (2009), a maquinaria viabiliza a materialização das funções intelectuais no processo produtivo. A via para se objetivar a generalização das funções intelectuais na sociedade foi a escola. Foi sob o impacto da "Revolução Industrial" que os primeiros países constituíram os seus sistemas nacionais de ensino, formando assim a escola básica. A Revolução Industrial corresponde a uma Revolução Educacional, colocando a máquina no centro do processo produtivo.

Com a introdução da maquinaria necessitava-se que os trabalhadores se capacitassem para integrar o processo produtivo. Quando eles já se encontravam em condições de 
conviver com as máquinas, era necessário também realizar atividades de manutenção, reparos, ajustes, assim como o desenvolvimento e adaptação às novas circunstâncias. Surgiram desta forma, no interior da produção, tarefas que exigiam determinadas qualificações específicas obtidas por um preparo intelectual também específico. Esse espaço foi ocupado pelos cursos profissionais organizados no âmbito das empresas ou do sistema de ensino, tendo como referência o padrão escolar, mas determinados diretamente pelas necessidades do processo produtivo.

Portanto, sobre a base geral e comum da escola. Assim o sistema de ensino se dividiu entre as escolas de formação geral e as de formação profissional. Esta é a situação que vem sendo estudada atualmente no contexto da chamada introdução de novas tecnologias. Pode-se dizer que se está vivendo aquilo que alguns chamam de Segunda Revolução Industrial ou Revolução da Informática ou Revolução da Automação. Antes, o que ocorreu foi a transferência das funções manuais para as máquinas, e o que está ocorrendo nesta nova fase é a transferência das próprias operações intelectuais para as máquinas.

Diz-se, então, que esta é a "era das máquinas inteligentes”. As qualificações específicas tendem a desaparecer, o que traz em contrapartida a elevação do patamar de qualificação geral. Importando de fato a formação geral sólida, a capacidade de manejar conceitos, o desenvolvimento do pensamento abstrato. As máquinas, como extensão dos braços e agora também do cérebro humano, não passam de instrumentos capazes de realizar operações complexas, amplas, e por tempo prolongado. Portanto, o homem que domina e controla, em última instância, continua sendo um trabalhador. Em suma, pode-se afirmar que o trabalho foi e continuará sendo o princípio educativo do sistema em seu conjunto.

Não se pode negar, portanto, que a incorporação de novas tecnologias por empresas brasileiras nas atuais circunstâncias, além de pôr o atraso em que se encontra em matéria de educação, terá o papel de universalizar a escola básica, antiga escola primária com o seu currículo já clássico para a construção de um sistema educacional unificado de acordo com as exigências da nova era em que se está ingressando.

\subsection{A Formação Profissional no IFCE}

A trajetória do Instituto Federal do Ceará se inicia no século $\mathrm{XX}$, inspirado nas escolas vocacionais francesas para o ensino profissional das populações de baixa renda. 
Com o passar das décadas e o processo de industrialização, o instituto que antes servira como escola de aprendizes de artífices, passou a denominar-se escola industrial de Fortaleza (IFCE, 2015). Em I968 a entidade em questão passa a se chamar Escola Técnica Federal do Ceará, sendo considerada a partir daí uma instituição voltada para a educação profissional de elevada qualidade, ofertando diversos cursos de nível médio nas áreas de Estradas, Eletrônica, Mecânica, Química Industrial, Telecomunicações, Turismo e Edificações (IFCE, 2015).

\subsection{Políticas Públicas Voltadas à Educação Profissional}

Em se tratando do fomento ao desenvolvimento e expansão da educação profissional, o poder público assume um papel de destaque. Essa importância é evidenciada pelas diversas ações e políticas públicas voltadas à educação profissional. O Estado, através da Secretaria Nacional da Juventude, Conselho Nacional da Juventude e a Secretaria de Educação Profissional e Tecnológica (SETEC), atuam como articulador entre entidades públicas, empresas privadas e as comunidades.

Segundo os autores Sousa (2014, 2016) e Lima (2017), dessa articulação surgem ações como expansão da rede federal de educação profissional e tecnológica; aceleração dos projetos do Programa de Reforma da Educação Profissional PROEP; implantação de novo modelo de gestão através do Programa de Formação Profissional Integrada de Jovens para o Mundo do Trabalho; instalação de novos centros públicos de formação profissional; apoio às 150 escolas agrícolas municipais que receberam verbas federais; financiamento para a expansão e modernização das instituições de educação profissional e tecnológica federais, estaduais e municipais.

O desenvolvimento de novas técnicas e métodos de ensino exige infraestrutura tecnológica adequada, tal infraestrutura demanda vultosos recursos monetários, tornando imprescindível a parceria público-privado. Nesse sentido, estudos propiciarão a identificação dos possíveis financiadores e da oferta e demanda da educação profissional no Brasil.

Outras políticas públicas que merecem destaque são o Fundo para Educação Profissional e tecnológica - FUNDEP e o Fundo de Extensão da Educação Profissional FEEP. Ambas as estratégias visam o apoio financeiro às instituições públicas. O FUNDEP foi aprovado em junho de 2006 pela Comissão de Educação do Senado Federal. Ele tem a 
finalidade de custear programas que ofereçam renda e emprego a jovens desempregados, sendo os seus objetivos norteadores os seguintes:

- Melhorar os serviços prestados, aumentar a competitividade profissional e elevar a renda do trabalhador;

- Qualificar, habilitar, especializar e aperfeiçoar as habilidades pré-existentes do trabalhador;

- Formar novos trabalhadores com habilidades especificas.

Os recursos do FUNDEP advêm basicamente de quatro áreas: 7\% do produto da arrecadação dos impostos sobre a renda e proventos de qualquer natureza; $5 \%$ dos recursos do Fundo de Amparo ao Trabalhador - FAT; I0\% dos recursos recolhidos pela previdência; e $18 \%$ do total dos recursos do FUST.

Já o FEEP, tendo em vista o baixo índice de alfabetização funcional no Brasil, foi criado em 2006 com a previsão de construção de trinta centros vocacionais tecnológicos, instalação de dois mil centros de inclusão digital, implantação de mil trezentos e cinquenta núcleos de informações tecnológicas e a contratação de dez mil setecentos e cinquenta bolsistas para o funcionamento dos centros e núcleos.

Por fim, temos de falar da que talvez seja a maior das políticas públicas voltadas ao ensino profissionalizante, o "Sistema S", surgido durante a "Era Vargas", este por sua vez é composto por: Serviço Nacional de Aprendizagem Industrial - SENAI e Serviço Social da Indústria - SESI; Serviço Nacional de Aprendizagem Comercial - SENAC e Serviço social do Comércio - SESC; Serviço Nacional de Aprendizagem Agrícola - SENAR; Serviço Nacional de Aprendizagem de Transportes Serviço Social em Transportes SEST; Serviço de Apoio à pequena e Media Empresa - SEBRAE, e o Serviço social das cooperativas de prestação de serviços - SESCOOP.

Todas estas instituições públicas citadas no parágrafo anterior dão ao Sistema um caráter heterogêneo. Apesar das semelhanças em alguns pontos, as entidades componentes do sistema possuem diferenças decorrentes do seu contexto de fundação e de sua articulação interna dentro do Sistema. As entidades são de natureza privada (gerida por sindicatos), mas recebem recursos públicos. Devido a presença de dinheiro público os conselhos do Sistema, tanto a nível nacional quanto regional, tem a participação de representantes dos Ministérios ou delegações regionais da Educação e do Trabalho.

Graças ao Sistema S diversos centros de tecnologia, escolas, centros de 
treinamento, de atendimento médico, social, recreativo, cultural, unidades móveis, postos de atendimento ao trabalhador e estabelecimentos-escola coexistem nesse âmbito. Devido a essa infraestrutura, diversos jovens e adultos já foram capacitados profissionalmente para o tão concorrido mercado de trabalho do Brasil.

Atualmente se constata que o avanço tecnológico e da informatização e o mundo passa por rápidas e profundas transformações. Essas mudanças trazem novas formas de produção, estão e consumo da força de trabalho transformando tarefas complexas que exigem do trabalhador a capacidade de diagnosticar e apontar soluções. Surgem então outras profissões que substituem as tradicionais e exigem a especialização do trabalhador, o desenvolvimento da capacidade de abstração para ler e interpretar dados. Desta forma, cresce os índices de desemprego e dificuldade de emprego.

A reestruturação dos mecanismos de qualificação e formação de trabalhadores na área de turismo está sendo exigido devido às constantes transformações na área. Com o crescente aumento de visitantes cresce a demanda por uma formação específica de cursos voltados para a área de turismo.

\section{O TURISMO E A EDUCAÇÃO}

Conforme Trigo (2009), o Animador Turístico constitui uma profissão que exige uma ampla formação e que abrange diversas áreas. Deve-se ter uma formação geral adequada, sendo necessário possuir entre outros conhecimentos: Gestão e administração, de acordo com os objetivos econômicos do estabelecimento; aspectos vinculados à segurança e prevenção de riscos e primeiros socorros; idiomas estrangeiros para facilitar sua relação com os clientes de países estrangeiros.

Segundo Trigo (2009) esclarece, também se inclui os conhecimentos de vocabulários específicos da profissão do animador turístico. Elementos de psicologia e sociologia para estimular o interesse dos turistas pelas atividades que podem ter a sua disposição; Geografia, Arte, História e Antropologia Social que lhe permita organizar excursões, visitas ou facilitar o contato com a população nativa; elementos diferenciadores em função do perfil dos turistas (terceira idade, crianças, jovens); possibilidades de distração suscetíveis a responder as necessidades de tranquilidade, novidades e enriquecimento espiritual dos clientes; relações públicas que permitirão oferecer a capacidade de integrar-se nos grupos e equipes de pessoas com a maior naturalidade e 
capacidade de trato com estes clientes; conhecimentos dos tipos de instalações de lazer coletivas que existem e o que podem utilizar para realizar suas atividades.

A educação e a formação do povo têm de passar pela conscientização dos mecanismos de exploração que os países mais ricos desenvolveram através da história para garantir a si mesmos privilégios de uma vida mais confortável. Contudo, essa conscientização não deve impedir a busca de melhores relações entre países ricos e pobres. Nesse mundo globalizado o país que ficar de fora desse círculo de relacionamento estará se arriscando a ficar sem capital, sem tecnologia e sem informação.

Trigo (2009) chama atenção para o fato de que o Brasil ainda se encontra bastante defasado nesse acesso à modernidade, quando se compara aos países desenvolvidos. Principalmente as atividades turísticas sentem a distância que separa o Brasil de outras nações. Necessita-se ter acesso ao capital, tecnologia e possibilidades de trabalho e de maior preparação de profissionais que atuam nesta área. Segundo Trigo (2009), a partir de I950 houve uma maior proliferação do turismo de massa e a partir de 1980 ocorreram alterações estruturais no mundo inteiro que permitiram que se repensasse sobre a importância do prazer nas sociedades agora denominadas pós-industriais.

A alta tecnologia e o poderio econômico dos países desenvolvidos possibilitaram investimentos para grandes projetos nas áreas de lazer e turismo, levando a grandes parcelas da população a novas opções de lazer e entretenimento. As novas tecnologias a serviço do entretenimento transformaram profundamente a estrutura de viagens, espetáculos, artes e esportes. A pressão do turismo internacional provoca, por sua vez, novos investimentos em transportes, construção de alojamentos, instalação de equipamentos de lazer e organização de maiores e complexos destinos turísticos, sejam para negócios, atividades acadêmicas, políticas ou de lazer.

Para se falar em preparação de profissionais para este setor terciário nas sociedades pós-industriais, significa compreender os paradigmas dessas sociedades e toda a complexidade existente para que se possa pensar em estruturar um projeto pedagógico ligado ao ensino de turismo, hotelaria, alimentos e bebidas ou entretenimento em geral.

Necessita-se delimitar algumas questões para que se possa compreender com profundidade as questões emergentes do setor terciário e as sociedades pós- industriais. Para isto, deve-se compreender como o mundo do trabalho sofreu uma profunda transição, desde a fase do capitalismo comercial até o capitalismo pós-industrial. Para poder traçar as 
novas propostas educacionais é necessário entender as novas faces do trabalho que balizam as grandes questões atuais.

Segundo Trigo (2009), em meados do século XX, o mundo do trabalho apresentou um quadro bastante definido quanto às suas transformações. Processou-se mudanças em virtude de novas tecnologias, e essas mudanças refletem na diminuição de postos de trabalhos, em aumento de desemprego e subemprego, na flexibilização da produção que gera novas relações profissionais, no surgimento de categorias profissionais antes inexistentes, especialmente no setor de serviços e informática, na diminuição da população economicamente ocupada no setor secundário, na hipertrofia do setor terciário e na valorização de atividades como o lazer.

Pode-se dizer que: "O turismo está ajudando a redesenhar as estruturas mundiais, influenciando a globalização, os novos blocos econômicos e em última análise, a nova ordem internacional” (TRIGO, 2009, p. 9). No século XX, as dúvidas permearam milhões de pessoas diante desse novo tempo. Entre a esperança da estabilização das novas democracias e das relações internacionais e o receio do colapso provocado por conflitos étnico-raciais, crises econômicas, desemprego estrutural e fundamentalismo religioso. Caminhou-se somente com uma certeza: o homem encontra-se em um novo tempo, com novas esperanças, novos desafios.

Com os novos tempos, pode-se destacar que o turismo tem sido uma força propulsora das mudanças e a educação como instrumento básico da cultura e da civilização. A situação mundial do setor de serviços no final do século $\mathrm{XX}$ aponta na direção de que a economia internacional está, em sua maior parte, assentada no vasto e complexo setor terciário, que abrange comércio, finanças, transportes, saúde, educação, publicidade e propaganda, administração pública e privada, comunicações, artes e cultura, lazer e turismo etc.

Um dado econômico relevante do setor de serviços é que, em vários países desenvolvidos, o setor de entretenimento é um dos que apresentaram maiores índices de crescimento na década de 1990. A revista norte-americana "International Business Week (de 14/03/1994) publicou a matéria de capa “The entertainment economy", sobre os Estados Unidos, usando dados do Bureau of Labor Statistics, a revista calculou que o setor de recreação e entretenimento empregou, em 1993, cerca de 200 mil trabalhadores nos Estado Unidos ou $12 \%$ da oferta total de novos empregos. 
Calcula-se ainda, que os norte-americanos gastaram neste mesmo ano, US\$ 340 bilhões em atividades de diversão como aluguel de vídeo, cassinos, parques temáticos e esportes. Neste valor não estão computados os gastos com viagens e turismo ou os gastos com pesquisa em alta tecnologia destinada à produção de jogos eletrônicos, CD-ROM, filmes para cinema e vídeo, informática aplicada aos sistemas de transportes e telecomunicações etc. São gastos feitos apenas em entretenimento.

Conforme Trigo (2009), o setor terciário é hoje predominantemente na economia mundial, o que principalmente o turismo e o lazer têm uma participação bastante prioritária na construção do Produto Interno Bruto (PIB) de vários países e no oferecimento de serviços para mercados cada vez maiores, além de oferecer postos de trabalhos cada vez mais exigentes em termos de habilidades profissionais. Em plena era “pós-industrial”, após as décadas de 1970 e 1980, ficou claro que o crescimento do lazer e do turismo ocorreu com mais intensidade.

Conforme Barreto (2006), o turismo é uma atividade multidisciplinar e interdisciplinar. Multidisciplinar porque o processo exige o concurso de uma ampla variedade de áreas do conhecimento; interdisciplinar, porque todas estas áreas devem estar interligadas. O turismo se vivencia hoje. Esta atividade, conforme o autor supracitado, começou como uma atividade pragmática, empresarial, descoberta praticamente por acaso por Thomas Cook, em meados do século XIX, e até hoje, em muitas empresas valoriza-se mais as experiências adquiridas no dia a dia do que um diploma de curso superior, numa demonstração evidente de que ainda não houve um acordo entre o mercado e o Sistema de Ensino.

O desafio é formar profissionais capazes de entender a totalidade do processo e intervir nele criativamente, e que, ao mesmo tempo, tenham conhecimento aprofundado de alguns dos aspectos da atividade turística, de acordo com a demanda por espera de especialistas, característica da pós-modernidade.

O problema que se apresenta é saber que tipo de evolução, no futuro, deve- se ministrar aos profissionais de turismo. Na América Latina, conforme Barreto (2006), o modelo mais utilizado tem sido modelo espanhol, que forma um profissional eclético, que pode atuar na área operacional ou técnica (aplicação de conhecimento) ou na de pesquisa ou científica (produção de conhecimentos novos, ensino, publicações).

Os currículos para formar este tipo de profissional incluem uma enorme quantidade 
de disciplinas que fazem parte do fenômeno turístico, que são necessários ao planejador, mas que podem ser prescindíveis em outras hierarquias, nas quais devem ser enfatizados aspectos operacionais.

\section{CONCLUSÃO}

Nos últimos anos a animação tem conseguido se colocar na categoria de primeiras preocupações na oferta de produtos turísticos. Tem-se tomado consciência de que para alcançar este objetivo e organizá-lo, é necessário profissionais qualificados, que sejam técnicos capazes de provocar mudanças de mentalidade no setor empresarial, para que possam reconhecer que esse profissional no intento deste fazer a diferença em seu estabelecimento, como produto que irá oferecer a satisfação ao cliente.

De acordo com as pesquisas, neste trabalho, esta profissão necessita de capacitação pessoal, de competências e habilidades e deve ser acessível para aqueles que sentem a animação como uma verdadeira vocação para o serviço. São nestes potenciais profissionais que as instituições formadoras como o IFCE, devem oferecer uma formação contínua de qualidade para chegar a esse produto, que tanto desejam os empresários e os clientes, e que hoje se encontra distante destas pretensões.

A formação profissional tem por objeto a capacitação para o exercício de uma profissão. A habilidade para o desenvolvimento das atividades que exige uma profissão se manifestará de formas muito diferentes: como capacidade para fazer frente a novas situações; na organização e planificação do trabalho; na inovação e destreza para abordar atividades que não são habituais ou rotineiras; na relação com diretores, outros empregados e clientes.

Tradicionalmente, a formação profissional tem estado tutelada em escolas ou institutos. A aquisição de competências e técnicas de trabalho constituem seu objetivo básico. É evidente que continua sendo importante esta etapa ou fase informativa, mesmo que a formação neste âmbito seja flexível no sentido de permitir a adaptação às novas circunstâncias, ajustando os planos de estudo, as especialidades.

De fato, uma das características mais generalizadas dos sistemas educativos e formativos é, precisamente, a acumulação de conhecimentos em um determinado período da vida, sem ter praticamente nenhum contato com o mundo trabalhista, sem conciliar a teoria com a prática, sem manter uma relação entre escola e empresa. Objetivando 
reverter este quadro é que são criadas hoje condutas para fazer com que o educando se aproxime mais da empresa para acompanhar assim a dinamicidade do processo. Entram no currículo escolar as práticas de trabalho e os estágios são incorporados como uma atividade a mais nos cursos. É cada vez maior o número de países que incorporam as práticas nas empresas.

O sistema formativo deve ser flexível e operativo, atendendo às necessidades de ajuste. A maior ou menor qualidade dos recursos humanos condiciona o resultado final dos projetos. Constatou-se que o Turismo passou a ser considerado pela maioria das pessoas como uma necessidade fundamental, pois o setor oferece oportunidades para evadir-se do cotidiano e para se descobrir novos mundos, novas pessoas e novas culturas. É certo que o grande fluxo de turistas acontece nos países mais desenvolvidos, porém surgem as necessidades e desejos de conhecer novos destinos turísticos.

Tal fato incentiva a atividade a estender-se a outros continentes, alcançando um âmbito internacional. Assim, países como o Brasil que apresentam um atrativo diferente dos países europeus ou mesmo Estados Unidos, passaram a ter sua indústria turística impulsionada consideravelmente.

Neste trabalho se aprofundou o estudo sobre o lazer, porque ele, hoje em dia, está sendo promovido como um produto consumível pelo marketing. As atividades de lazer podem vir a ser determinadas pelas possibilidades e hábitos de consumo. Os jornais dos tempos atuais geram novos hábitos e costumes que podem prejudicar na economia doméstica e na cultura familiar, isso porque eles gostam do que está na moda, eles querem algo, porque os seus amigos têm, não importando que seja caro ou não. Os pais por outro lado, com medo de que os filhos fiquem frustrados, trabalham em demasia para que o filho tenha o que quiser.

A geração jovem de hoje é muito influenciada pela televisão, pela Internet; elas querem ter, consumir. Os meios de comunicação propagam o entretenimento e massificam o lazer, associando-o a recreação e eventos de massa, fazendo com que as pessoas tenham uma visão limitada e parcial do que é lazer. A diversão e o lúdico são traços de todas as sociedades conhecidas, em todas as épocas da história, e podem acontecer em qualquer momento cotidiano dos indivíduos, estejam eles trabalhando, trocando fraldas ou rezando. Já o tempo livre é uma conquista moderna das lutas sindicais, da revolução técnica do trabalho e a pressão da sociedade concretamente, é o tempo que sobra das obrigações 
profissionais, escolares e familiares, inclusive englobando o estudo voluntário, a participação religiosa ou política e o lazer.

O tempo do lazer não é o único tempo em que podemos experimentar momentos felizes, mas é um tempo de lazer em que podemos buscar mais situações agradáveis do que aqueles que o trabalho pode nos proporcionar. Vivemos uma civilização de tempo livre, em que já é quase igual e às vezes maior do que o tempo de trabalho.

\section{REFERÊNCIAS}

BARRETO, Margaritta. Manual de iniciação ao estudo do turismo. Campinas (SP): Marketing, 2006.

LIMA, Jean Custodio de. Fortaleza: Premius, 2017.

SAVIANI, Dermeval. O trabalho como princípio educativo frente às novas tecnologias. In: FERRET. Celso João (org.) et al. Novas tecnologias, trabalho e educação: um debate multidisciplinar. ed. 6. Petropolis: Vozes, 2009.

SAVIANI, Dermeval. A nova lei da educação: trajetória, limites e perspectivas, ed. 3, Campinas (SP): Autores Associados, 2009.

SETUR - Governo do Estado do Ceará. O turismo: uma política estratégica para odesenvolvimento sustentável do Ceará. Fortaleza, 2008.

SOUSA, Antonia de Abreu. A educação profissional: Ensaios sobre a formação e qualificação dos trabalhadores. Recife, 2016.

SOUSA, Antonia de Abreu. Educação Profissional: Analise contextualizada. Fortaleza, 2014.

TRIGO, Luiz G. Godoi. Turismo e qualidade: tendências contemporâneas. Campinas: Papirus, Coleção Turismo. 2009. 